\title{
Editorial
}

\section{Missão Comprida Cumprida}

\author{
"A vida só pode ser compreen- \\ dida olhando-se para trás; mas \\ só pode ser vivida olhando-se \\ para a frente"
}

Soren Kierkegaard

Encerramos o mandato estendido desta diretoria da revista Psicologia: Teoria e Pesquisa, tendo cumprido nossa missão no interstício de três anos (setembro de 2005 a setembro de 2008). Como é típico de todo final de ciclo, cabe aqui uma recapitulação e um balanço do que representou tal período, no que se refere às publicações científicas da área da psicologia e saberes afins divulgados na revista.

Primeiramente, o compromisso precípuo de divulgar a produção científica de qualidade na área de psicologia e domínios afins resultou na publicação de 12 números, dos quais 11 foram números correntes e um número especial. Este último foi dedicado aos professores laureados, em sinal de reconhecimento de suas responsabilidades na construção da ciência psicológica brasileira e conseqüente projeção da excelência da Universidade de Brasília, que se reflete além das fronteiras do território nacional.

Ao todo foram produzidas 1.582 páginas e publicados 155 artigos inéditos, nove resenhas, sete notícias. Ainda, no número especial, foram publicadas cinco reedições de artigosreferência, publicados nos primeiros números desta revista e uma entrevista. Foram produzidos 6.000 exemplares impressos e 792 CD-ROMs. Coube a esta diretoria, o desafio e a conquista de ampliar a periodicidade da revista, passando de quadrimestral para trimestral. Esta gestão também foi responsável pelo aumento na média de artigos inéditos publicados por número (da ordem de 13,3), que se soma à resposta às demandas da prolífera produção intelectual da área de psicologia.

No que tange à distribuição geográfica das afiliações institucionais dos autores que contribuíram com artigos nos três últimos anos, temos um número razoável de autores de instituições estrangeiras (9\%), dos quais a maioria procedente de instituições de pesquisa e ensino superior da Europa (14) e Estados Unidos (5). A distribuição das afiliações institucionais no território nacional se concentra, em ordem decrescente, nas regiões sudeste (42\%), centro-oeste $(18,5 \%)$, sul $(16,6 \%)$, nordeste $(9,6 \%)$ e norte $(4,2 \%)$. Os artigos publicados foram majoritariamente em língua portuguesa, tendo havido publicação de artigos em língua francesa, língua inglesa e língua castelhana. No que tange à co-autoria, tem-se observado um incremento no número de artigos escritos de múltipla autoria, predominando a modalidade de dois autores.

Neste número, as contribuições para a área educacional foram bastante sortidas: Alysson M. Carvalho e Arlete S. Pereira avaliam a qualidade dos ambientes de educação infantil de um programa público. Cláudia Cardoso-Martins e Marcela F. Corrêa investigam a evolução da escrita em crianças em idade pré-escolar, por um período de aproximadamente dois anos. Cynthia B. Okano e Sonia R. Loureiro pesquisam o valor de proteção de um programa de suporte psicopedagógico para crianças que apresentam dificuldades escolares avaliado em dois momentos: nas séries iniciais e após três anos. Por sua vez, um interessante estudo no contexto do desenvolvimento humano é apresentado por Larissa S. Turtelli e Maria da Consolação G. C. F. Tavares, que apresentam uma discussão dos estudos de Kestenberg, abordando a interligação entre o movimento e o desenvolvimento humano.

Estudos envolvendo participantes com necessidades especiais são apresentados em dois artigos relevantes: Fernanda Saviani-Zeoti e Eucia B. L. Petean apresentam estudo que teve por objetivo conhecer a opinião de adultos com deficiência mental leve e de seus cuidadores em relação à qualidade de vida desses deficientes. Priscila M. de Araújo e Paulo R. S. Ferreira avaliaram um procedimento para o ensino de subtração a indivíduos deficientes mentais, por meio de relações ambientadas em tarefas de escolha de acordo com o modelo.

$\mathrm{Na}$ área de psicometria e avaliação neuropsicológica, uma grande variedade de contribuições se apresentam neste número. Tania F. Campos, Soraya M. de Carvalho, Luciana P. de Melo e Ana Carolina A. Lima verificam a concordância de nomeação e familiaridade de um conjunto de figuras de objetos e de atividades funcionais. Taciano L. Milfont, Valdiney V. Gouveia, Girlene R. de Jesus, Estefânea E. S. Gusmão, Sandra S. S. Chaves e Jorge A. P. de M. Coelho investigam a comprovação da estrutura fatorial da Escala de Atitudes diante de Relacionamentos Afetivos Estáveis em estudantes universitários. Denise R. Bandeira, Adriane X. Arteche e Caroline T. Reppold estudaram a validade convergente da escala de Autopercepção de Harter em estudantes do Ensino Médio. Tin Po Huang e Gerson A. Janczura verificaram o efeito do tipo de teste e tempo de apresentação dos estímulos durante a codificação na produção de falsas memórias.

Um estudo clínico que trata de distúrbio alimentar é apresentado por Paulo R. Abreu e Luciana R. D. Cardoso, por meio de estudo de caso de um paciente do sexo masculino diagnosticado com anorexia nervosa, para ilustrar e elucidar o debate, por apresentar características diagnósticas diferentes das usualmente relatadas na literatura.

Duas contribuições no âmbito da psicologia jurídica são apresentadas neste número. Luciane M. Raupp e Clary Milnitisky-Sapiro apresentam os resultados de uma investigação que visa analisar o tratamento destinado a adolescentes em uma comunidade terapêutica. Por sua vez, Madge Porto descreve a trajetória da reconstrução da proposta de intervenção psicológica em um abrigo para mulheres em situação de violência intrafamiliar e de gênero.

Por sua vez, no âmbito das questões epistemológicas, Robson N. da Cruz e Eduardo N. P. de Cillo apresentam um ensaio no qual buscam uma possível interpretação e contextualização do desenvolvimento do behaviorismo radical para refutar a tese de sua postura eminentemente mecanicista.

Para encerrar, Marco Aurélio Togatlian apresenta a resenha do livro intitulado Afetividade e Práticas Pedagógicas, organizado por Sérgio Leite, no qual destaca a relação entre afetividade e práticas pedagógicas. 
Agradeço a todos aqueles que colaboraram com a revista nesse período e que, junto comigo, escreveram uma pequena parte da história da revista: meus colegas de diretoria, os estagiários, os indispensáveis conselheiros, os solícitos pareceristas ad hoc, a direção e os funcionários do Instituto de Psicologia, os autores de manuscritos, as agências de fomento...

Entrego com total confiança a responsabilidade pela continuidade na condução dos trabalhos da revista para Josele Abreu Rodrigues, que com certeza honrará, com a seriedade e competência que lhe são características, o posto de nova editora da revista. Quero expressar à nova equipe meus votos de muito sucesso nessa árdua e desafiante missão editorial.

Despeço-me aqui, desejando aos caros leitores que uma vez mais desfrutem da leitura de um novo número da revista e agradeço pela companhia e interlocução ao longo da trajetória dos três últimos anos.

\section{Maria Inês Gandolfo Conceição \\ Editora}

\section{Conselho Editorial (2006 - 2008)}

Adriana Wagner (PUC-RS)

Ana Cristina Costa de Figueiredo (UFRJ)

Ângela Maria de Oliveira Almeida (UnB)

Antonio Pedro de Mello Cruz (UnB)

Domingos Sávio Coelho (UnB)

Emmanuel Zagury Tourinho (UFPA)

Eveline Maria Leal Assmar (UGF)

Gérson Aparecido Yukio Tomanari (USP)

Leandro de Lajonquière (USP)

Lúcia Rabello de Castro (UFRJ)

Maria Izabel Tafuri (UnB)

Mário César Ferreira (UnB)

Tereza Cristina Cavalcanti Ferreira de Araújo (UnB)

Terezinha de Camargo Viana (UnB)

Valdiney Veloso Gouveia (UFPB)

Wanderley Codo (UnB) 